Running head: Child-like doll ownership

\title{
Exploring the ownership of child-like sex dolls
}

\author{
Craig A. Harper*1 \& Rebecca Lievesley ${ }^{1}$
}

${ }^{1}$ NTU Psychology, School of Social Sciences, Nottingham Trent University (UK)

* Correspondence related to this article should be directed to Dr. Craig Harper, NTU

Psychology, School of Social Sciences, Nottingham Trent University, 50 Shakespeare Street, Nottingham, NG1 4FQ, UK.

Email: craigaharper19@gmail.com Tel.: +44 (0)1158484718 Twitter: @CraigHarper19 


\begin{abstract}
There is a fervent social debate ongoing that relates to the ownership of child-like sex dolls. On the one hand, some proponents of dolls suggest that they offer a safe sexual outlet for minor-attracted people (MAPs) and could be used in efforts to prevent the sexual abuse of children. On the other side of the debate, child-like dolls are seen as articles that sexualize children, encourage deviant fantasies, and increase offending risk. To date, no empirical analyses have been undertaken with people who own such dolls. In this paper we present data from child-like sex doll owners $(n=85)$ and MAPs who do not own dolls $(n=120)$. Specifically, we compared their psychological characteristics and proclivities for sexual aggression. Among non-owners, almost $80 \%$ of participants declared an interest in owning a sex doll, which is higher than in adult-attracted samples of non-owners. We found few differences between the groups on most personality variables, with doll owners being less antisocial and anxiously-attached than non-owners, but exhibiting more schizotypal traits. Related to offending proclivities, doll ownership was associated with lower levels of sexual preoccupation and self-reported arousal to hypothetical abuse scenarios, but higher levels of sexually objectifying behaviors and anticipated enjoyment of sexual encounters with children. We discuss these data in relation to a functional model of child-like sex doll ownership among MAPs.
\end{abstract}

Keywords: sex dolls; minor attraction; sexual satisfaction; sex toys; sexual abuse 
Exploring the ownership of child-like sex dolls

\section{Introduction}

Among sex research (and broader societal discussions related to sexuality), few topics are currently as polarizing as themes related to sexual attractions to children and the ownership of sex dolls. Indeed, controversies related to the study of minor-attracted people (MAPs) have led to academic dismissals and widespread public backlash (see Asbury, 2021), while State- and national-level legislatures have crafted new laws to restrict the legal ownership of sex dolls in recent years (Prostasia Foundation, 2021). Although we are beginning to understand that there is a range of both sexual and non-sexual ownership of sex dolls among teleiophilic individuals (i.e., those whose sexual attractions are directed towards adults), nothing is currently known about those who own child-like sex dolls (for a review of the literature, see Harper \& Lievesley, 2020). Similarly, we do not know anything about the desire for such dolls among those who are sexually attracted to children. In this paper we present an initial snapshot of the psychological characteristics that are associated with the ownership of child-like sex dolls, and contribute some initial empirical data to ongoing debates about the potential associations between doll ownership and risks related to the sexual abuse of children. In doing so, we sought to answer three over-arching questions:

1. What is the rate of interest in owning child-like sex dolls among MAPs who currently do not have such a doll?

2. Are those who own child-like sex dolls distinguishable from MAPs who do not own such dolls in relation to relevant psychological constructs (e.g., disordered personality traits, attachment difficulties)?

3. Is there any evidence that the owners of child-like sex dolls present an increased risk of sexual offending in comparison to MAPs who do not own dolls? 


\section{What Do We (Not) Know about Child-Like Sex Doll Ownership?}

Although the extant literature on the ownership of sex dolls is still in its infancy, the available analyses focus on those who own adult-like dolls (Ferguson, 2014; Harper et al., 2022; Langcaster-James \& Bentley, 2018; Su et al., 2019; Valverde, 2012). This means that we know very little about the motivations of those who own child-like dolls, or the effects that such dolls have on psychological states and subsequent behaviors. From a philosophical perspective, Danaher (2019) examined the issue of child-like sex dolls using the lens of legal moralism, citing how the perceived immorality of child-like dolls should act as a basis for their restriction or criminalization, irrespective of the level of objective harm they cause. In doing so, he drew on Strikwerda's (2017) work to argue that engaging in sexual activity with a child-like sex doll not only encourages and normalizes sexual activity with children, but that it also indicates a lack of moral virtue among the owners of such dolls (see also Danaher, 2017). Relatedly, the ownership of child-like sex dolls has been cited as causing social or cultural harm, with Chatterjee (2020) arguing:

“... permitting a trade in even abstract child sex dolls and robots could be seen as sanctioning and facilitating a public atmosphere that encourages the portrayal of children as sexual objects, and the acceptance and normalization of child abuse" (p. $34)$.

Although this is a logical argument to make in light of the evidence related to the conditioning of paraphilic sexual interests (see Pfaus et al., 2020), it fails to acknowledge the potential for dolls playing a role in the prevention of child sexual abuse. Some professionals have tentatively made this argument (for a summary, see Rutkin, 2016), but it has generally been rejected without much detailed discussion of its validity. In one review of these arguments, the Australian Institute of Criminology (which operates as a branch of the 
Australian Government) commissioned a report into the effects of child-like sex dolls, specifically in relation to:

1. the promotion of the sexualization of children

2. the extent to doll ownership indicated an escalation from child sexual exploitation material (CSEM) use

3. the association between child-like sex doll ownership and contact sexual offending against children)

4. the use of child-like sex dolls as a tool for the sexual grooming of children.

In the final report, Brown and Shelling (2019) were explicit in their lack of identification of any empirical evidence for any specific hypothesis about the effects of childlike doll ownership (see also Harper \& Lievesley, 2020). However, they concluded that:

\footnotetext{
"It is reasonable to assume that interaction with child sex dolls could increase the likelihood of child sexual abuse by desensitizing the doll user to the physical, emotional and psychological harm caused by child sexual abuse and normalizing the behavior in the mind of the abuser. At the same time, there is no evidence of therapeutic benefit from child sex doll use.” (Brown \& Shelling, 2019, p. 8)
}

As alluded to above, it is plausible that child-like doll ownership is in some way (at least on a theoretical level) associated with proclivities for child sexual abuse. However, it is equally plausible that doll ownership is associated with child abuse prevention. It is, therefore, concerning that a government-supported agency would seek to promote one side of this debate and downplay the validity of the other, while simultaneously explicitly highlighting the lack of evidence in relation to either hypothesis. Such a conclusion was also reached by Cox-George and Bewley (2018), who purported to assess the implications of the use of sex dolls and robots on patients and professionals in healthcare settings. Again, after 
their literature search explicitly uncovered no empirical data, they discussed the risks of using dolls in terms of law enforcement interests in dolls, the potential for healthcare providers to be prosecuted for providing illicit materials, and the incitement of public backlash.

\section{Dolls as Protective, Risky, and/or Functional?}

With the above arguments in mind, Harper et al. (2022) set out three potential models of sex doll ownership that are linked to the issue of risk. We outline these below.

\section{Model 1: 'Dolls as protective'}

The first potential model of child-like sex doll ownership purports that dolls could be protective of sexual aggression by offering a safe sexual outlet for those who experience sexual attractions to children. Although the cathartic potential of dolls has never been explored empirically, there is some evidence that access to mainstream pornography is associated with lower rates of sexual violence at the societal level (Ferguson \& Hartley, 2009, 2022) which is potentially indicative of people seeking sexual gratification in pornography rather than via the coercion of living victims. Similar trends have been found in relation to child sexual exploitation material, with there being no direct evidence for a link between the consumption of sexually explicit materials depicting children and subsequent engagement in abusive behaviors (Diamond et al., 2011; Seto \& Eke, 2005; Seto et al., 2011). Within the context of child-like sex doll ownership, it is possible that being able to own a doll that resembles a preferred sexual target (regarding perceived age or specific physical characteristics) could help some MAPs to achieve sexual satisfaction and to reduce sexual fantasy engagement about real children (Moen \& Sterri, 2018; Rutkin, 2016).

\section{Model 2: Dolls as risk-enhancing}

Contrary to the view that child-like sex dolls could reduce the likelihood of owners abusing children, some theorists argue that dolls have the potential to increase owners' risk 
levels. At the heart of this view is a tolerance argument akin to a sex addiction model (for a review and commentary, see Hall, 2021), wherein dolls reinforce sexual attractions to children and, over time leads to a need to engage sexually with real children to achieve the same level of satisfaction. Like the argument that dolls may be protective, this risk-enhancing hypothesis has not been empirically tested but is concluded in various legal and sociological treatises about the legal status of child-like sex doll ownership (e.g., Brown \& Shelling, 2019; Chatterjee, 2020; Cox-George \& Bewley, 2018; Danaher, 2017, 2019; Strikwerda, 2017).

It is possible that the rehearsal of sexual fantasies and the reinforcement obtained via orgasm could serve to strengthen sexual attractions to children (Arrigo \& Purcell, 2001; Pfaus et al., 2020), as well as contributing to the development of implicit theories that are supportive of their sexual abuse (for reviews, see Bartels \& Merdian, 2016; Ward \& Keenan, 1999). For example, having on-demand sexual access to a sex doll that resembles a child could increase beliefs related to the need for sexual activity when aroused (known as the 'uncontrollable sex drive' implicit theory), as well as exaggerated levels of sexual entitlement. Given the advances in AI-enhanced sex robots, there may also be the possibility for perceived consent from some robots resembling children that might increase the perception of owners that children are sexual beings who can give valid consent to sexual activity, with this view being associated with more permissive attitudes about, and a greater proclivity for, offending behavior (Dawson et al., 2009; Mihalides et al., 2004; Ward \& Keenan, 1999).

\section{Model 3: Dolls as functional life tools}

Away from associations with sexual risk, child-like sex dolls may serve other functions for the people who own them. Of course, there is a primary sexual function for sex dolls in a general sense (Ferguson, 2014; Harper et al., 2022; Langcaster-James \& Bentley, 2018; Valverde, 2012), and it is plausible that this masturbatory use of child-like models is also 
important for MAPs who own dolls. However, this need not reflect any association (positive or negative) with risks for offending. We also know that men who own sex dolls have nonsexual reasons for doing so, including those that relate to emotional closeness and a lack of viable real intimate partners (Ferguson, 2014; Harper et al., 2022; Su et al., 2019; Valverde, 2012). This may be more pronounced among MAPs who are motivated to own dolls for forming intimate attachments and to provide care for, such as a natural parental instinct in many people (Geary \& Flinn, 2001). Given their sexual attractions, it may be difficult for some MAPs to form and maintain intimate relationships with age-appropriate adults, and thus they may miss out on raising children in the kinds of ways that teleiophilic individuals do. Child-like dolls offer them the opportunity to mimic these processes in surrogate parental relationships where sexual motivations for ownership may be secondary. A subsequent potential effect of having a 'child' (in doll form) to care for, or to achieve sexual satisfaction with, is an increase of overall life satisfaction and wellbeing. Wellbeing is often a by-product of both life satisfaction (Fergusson et al., 2015) and sexual satisfaction (Carcedo et al., 2020), with all of these being considered primary human goods within the good lives framework (see Ward \& Gannon, 2006; Ward \& Marshall, 2004). As such, dolls need not be positively or negatively related to sexual risk but may instead be seen as a functional part of the lives of individuals who, through their sexual attraction patterns, are unable to live such full lives with real partners or children.

\section{The Current Study}

With these three models in mind, in this exploratory work we present an initial snapshot of the ownership and use of child-like sex dolls using an anonymous online survey. Specifically, we sought to explore the personality characteristics of such individuals, as well as their levels of sexual risk relative to a non-owner comparison sample of people who are sexually attracted to children. From the outset we did not begin with any specific hypotheses 
or expectations about the kinds of traits or behaviors that might be more prevalent among individuals who own child-like dolls. We are also open to the suggestion that dolls could be risk-enhancing, risk-reducing, or risk-neutral (or indeed that dolls may have a different relation to risk for each individual owner). In this work we hoped to establish a baseline for the types of constructs that may be relevant to child-like doll ownership, and to inform the sound design of future research efforts in this area.

\section{Methods}

\section{Participants}

The data reported here stem from a larger project into the psychology of sex doll ownership with over-arching aims of exploring the psychological characteristics of individuals who own sex dolls, and their relative levels of sexual risk in comparison to nonowner comparison samples. Analyses of men who own adult-like sex dolls have already been published in Harper et al. (2022), with the data reported here referring to those participants who were directed by the survey software into the 'child-like dolls' branch of the survey. Eligibility for this branch included the self-declared ownership of at least one child-like sex doll, or self-declared sexual attractions to children. Branching participants in this way enabled us to recruit doll owners and comparison groups using a single anonymous survey link, while still only displaying relevant measures to each subgroup. Women were excluded from the study owing to the gendered nature of doll ownership (Harper \& Lievesley, 2020; Langcaster-James \& Bentley, 2018; Middleweek, 2021).

To recruit participants, we placed study adverts on prominent web forums for individuals who own sex dolls, including boards on popular microblogging and social media platforms $^{1}$, and on two international online forums for individuals with sexual attractions to

\footnotetext{
${ }^{1}$ To protect participants' anonymity in this research project, we assured them that we would not reveal the specific names of the forums and websites that were used for recruitment.
} 
children seeking peer support. After removing all cases within the dataset with either no data or a negative response to the informed consent question, we were left with a final sample of 205 men who either (a) owned at least one child-like sex doll $(n=85)$, or (b) were attracted to children but did not own any form of sex doll $(n=120)$. The demographic characteristics of each subgroup are presented in Table 1.

Table 1. Demographic characteristics, by group

\begin{tabular}{lcc} 
& \multicolumn{2}{c}{ Group } \\
\cline { 2 - 3 } Variable & Doll Owners & Non-Owner MAPs \\
\hline Age (years) & $37.8( \pm 13.6)$ & $33.7( \pm 13.8)$ \\
Country & & \\
USA & $31(37.3 \%)$ & $38(33.9 \%)$ \\
UK \& Ireland & $4(4.8 \%)$ & $14(12.5 \%)$ \\
Canada & $2(2.4 \%)$ & $9(8.0 \%)$ \\
Australia / New Zealand & $0(0.0 \%)$ & $6(5.4 \%)$ \\
Mainland Europe & $40(48.2 \%)$ & $33(29.4 \%)$ \\
Other & $6(7.2 \%)$ & $12(10.7 \%)$ \\
Relationship status & & \\
Single (no current relationship) & $64(76.2 \%)$ & $83(70.9 \%)$ \\
Married & $7(8.3 \%)$ & $6(5.1 \%)$ \\
Divorced & $8(9.5 \%)$ & $11(9.4 \%)$ \\
Partnered (unmarried) & $5(6.0 \%)$ & $17(14.5 \%)$ \\
Declared age orientation & & \\
Adults-only & $5(5.9 \%)$ & $0(0.0 \%)$ \\
Children-only & $15(17.9 \%)$ & $34(28.3 \%)$ \\
Both (non-exclusive attractions) & $64(76.2 \%)$ & $86(71.7 \%)$ \\
\hline Note. Data reded 'Ag' repr) &
\end{tabular}

Note. Data related to 'Age' represent the mean age within each sample, with \pm 1 SD in parentheses. All other data represent frequencies, with the percentage equivalent (within the subgroup) in parentheses. Percentages may not always equal $100 \%$ due to rounding.

\section{Materials}

\section{Demographics}

We asked participants to provide minimal demographic information to help them to remain anonymous. However, basic information as requested, including sex (male / female), age (in years), relationship status (coded into 'single', 'married', 'divorced', and 'partnered'), country of residence, and sexual orientation for age (adults-only / children-only / both). 


\section{Doll-related variables}

We asked participants to self-report their doll owner status (yes / no). If a participant said that they did own at least one sex doll, they were asked about the type of doll (adult-like / child-like / both), the number of dolls owned, and how long they had owned dolls for. We also asked participants to rate the functions of their dolls as a way to measure how dolls were being used. Using an eleven-point sliding scale anchored from 0 (not at all) to 10 (very much), doll owners rated how much they used their doll(s) for sexual purposes, for nonsexual purposes (e.g., companionship), and for other purposes. The latter option also provided a free-text box for participants to elaborate on these broader doll functions. We also asked how often, in an average month, owners had sex with their doll(s). Non-owners were asked whether they would consider owning one using a binary yes-no response option.

\section{Sexuality-related variables}

We used Snell and Papini's (1989) Sexuality Scale to measure different facets of participants' engagement with sexuality. This measure has subscales for sexual self-esteem (e.g., "I am confident about myself as a sexual partner"; $\alpha=0.91$ ), sexual preoccupation (e.g., "I think about sex a great deal of the time"; $\alpha=0.89$ ), and sexual depression (e.g., "I feel down about my sex life"; $\alpha=0.88$ ). There are ten items per subscale, with participants rating each item on a scale ranging from -2 (strongly disagree), through 0 (neither agree nor disagree), to +2 (strongly agree). We calculated an average item score for each subscale. We also asked participants how often, in an average month, they had partnered sexual activity.

\section{Personality traits}

To examine personality traits exhibited by our participants, we used Hain et al.'s (2016) Personality Styles Inventory, which has subscales for measuring the following DSM-related personality clusters: 
- Schizotypal personality (e.g., "I often have sudden inspirations"; $\alpha=0.56$ )

- Borderline personality (e.g., "My feelings often change abruptly and impulsively"; $\alpha=0.53$ )

- Narcissistic personality (e.g., "Being the center of attention really appeals to me"; $\alpha=0.47)$

- Avoidant personality (e.g., "When I feel observed, I become anxious"; $\alpha=0.64$ )

- Obsessive-compulsive personality ("I am a person with fixed habits"; $\alpha=0.57$ )

- Antisocial personality (e.g., "People who want to harm me can count on my retaliation"; $\alpha=0.62$ )

Each cluster is measured using six items, with these being rated using a four-point scale anchored from 1 (does not apply at all) to 4 (fully applies). We calculated an average score for each cluster for each participant.

\section{Emotional experience}

Participants completed Watson et al.'s (1998) Positive and Negative Affect Scale to provide an index of their experience of emotion. This measure contains a list of 16 different emotions, with participants stating how often they experienced each of these in the preceding week. Ratings for ten positive emotions (e.g., excited, strong, proud) and ten negative emotions (e.g., upset, guilty, ashamed) were collected using a seven-point scale scored from 1 (very slightly or not at all) to 7 (extremely). We first calculated an average score for positive and negative emotions separately, before subtracting the negative score from the positive score. This led to a composite index of emotionality $(\alpha=0.85)$, where positive scores equated to more positive emotional experiences, and negative scores indicated more negative emotional experiences. 


\section{Attachment styles}

We used Gillath et al.'s (2009) State Adult Attachment Measure to obtain an indication of participants' attachment styles. This measure contains subscales that measure traits associated with a secure attachment style (e.g., "I feel like I have someone to rely on"; $\alpha=$ 0.89) and anxious-insecure attachment style (e.g., "I wish someone would tell me they really love me"; $\alpha=0.88$ ), and an avoidant-insecure attachment style (e.g., "The idea of being emotionally close to someone makes me nervous"; $\alpha=0.80$ ). Each subscale contains seven items, which are scored using a seven-point scale anchored from 1 (strongly disagree) to 7 (strongly agree). For each participant, we calculated an average score for each attachment style.

\section{Sexual objectification}

We used the Interpersonal Sexual Objectification Scale - Perpetrator Version (Gervais et al., 2018) to measure the extent to which participants had engaged in sexual objectification during the past twelve months. This is a 15 -item measure that asks participants to rate how often in the past year they engaged in a range of behaviors (e.g., "Stared at someone's breasts/chest when you are talking to them") using a five-point scale anchored from 1 (never) to 5 (almost always). An average score across all items was calculated to provide an index of sexual objectification $(\alpha=0.83)$.

\section{Sexual offending proclivity and past offending behaviors}

We asked participants to complete the Interest in Child Molestation Scale (Gannon \& O'Connor, 2011) to gauge their levels of hypothetical interest in engaging in the sexual abuse of children. This is a measure consisting of five sexual abuse scenarios, which are each followed by three questions pertaining to (1) anticipated levels of sexual arousal, (2) anticipated intention to engage in the stated behavior, and (3) anticipated enjoyment of 
engaging in the behavior. All questions are rated using a 1-7 scale, with higher scores indicating greater levels of sexual arousal, behavioral intention, and anticipated enjoyment, respectively. We calculated a general index of 'interest in child molestation' by averaging all 15 responses $(\alpha=0.94)$, as well as separate indices of 'arousal' $(\alpha=0.89)$, 'behavior' $(\alpha=$ $0.88)$, and 'enjoyment' $(\alpha=0.92)$.

We also asked participants whether they had ever engaged in sexual offending since the age of 18 years. We specifically asked whether participants had had sex with somebody who had not been consenting, whether they had sexual contact with a person below the age of 16 years, and whether they had obtained or viewed sexual images depicting children. As fillers, we also asked about whether participants had acted violently towards another individual or whether they had ever stolen something. In relation to each offending behavior, participants answered either 'yes', 'no', or 'unsure'.

\section{Procedure}

Adverts for participation were placed on forums that are known to be frequented by both doll owners and MAPs, with these highlighting the study's aim of exploring the psychological characteristics of those who own sex dolls. Interested individuals could click on the link which took them to the first page of the survey, and an overview of the project. The survey was hosted on SoSciSurvey to allow for the use of IP-blocking Tor browsers, which are commonly used by MAPs taking part in survey research. Upon providing their consent to take part, participants first completed the demographic and doll-related questions, before completing all other study scales in a randomized order. No questions were mandatory, save for the initial consent procedure. Upon completion of the survey, participants were presented with a comprehensive debriefing screen and links to relevant support services. In line with our institutional ethical approval, all participant data was included if they completed at least one of the study scales. Participants were asked to contact 
the research team using an anonymous email or letter (citing their unique participant code, which was self-produced after providing their consent) if they wish to withdraw. Specific subsample sizes for individual scales are presented in Table 3.

\section{Results}

We conducted our analyses in three stages. In the first stage we provide some baseline statistics about the ownership of child-like sex dolls, particularly in relation to their functions for owners. Stage two led to us using simple between-groups tests to establish whether on a general level the two groups differed on our measured variables. This involved us running a series of chi-square and $t$-tests. We then ran a binary logistic regression at stage three to explore the prediction of group membership by each of our measured variables while simultaneously controlling for the rest of the data. Given the exploratory nature of our analyses and the independence of each test that was run, we did not make any $p$-adjustments (for a discussion of the nature of $p$-value adjustments in exploratory research, see Rubin, 2017).

\section{The Functions of Dolls for Owners}

We began by exploring the information provided by child-like doll owners in relation to the functions of their dolls. We specifically asked doll owners to rate the 'sexual' and 'emotional' functions of their dolls, before giving an option for rating 'other' functions along with a free-text input opportunity. We ran a one-way analysis of variance (ANOVA) to examine the differences in function endorsement with the outcome of this not being statistically significant, $F(2,142)=2.75, p=.068, \eta^{2}=0.03$. This suggests that child-like doll owners are equally using their dolls for sexual reasons $(M=6.67, S D=3.15)$, emotional reasons $(M=6.11, S D=3.44)$, and 'other' reasons $(M=5.12, S D=3.80)$. We then looked at the free-text responses accompanying the 'other' reasons to look for themes. Prominent other 
reasons for child-like doll ownership included 'photography and art' $(n=17 ; 20 \%$ of doll owners), 'non-sexual intimacy' ( $n=17 ; 20 \%$ of doll owners), 'hobbies' ( $n=8 ; 9.4 \%$ of doll owners), 'non-sexual fantasy play' ( $n=4 ; 4.7 \%$ of doll owners), 'non-intimate care' $(n=2$; $2.4 \%$ of doll owners), 'improving quality of life' ( $n=2 ; 2.4 \%$ of doll owners), and 'preventing offending behavior' ( $n=1 ; 1.2 \%$ of doll owners).

On average, doll owners had sex with their dolls 8.08 times per month $(S D=9.63 ; M d n$ $=5$ times), which was significantly higher than the number of times they engaged in partnered sexual activity $(M=1.91$ times, $S D=4.97, M d n=0$ times $), t(72)=6.49, p<.001$, $d=0.76$. Related to the potential function of dolls as a route to achieving sexual satisfaction among MAPs, we found that $79.2 \%$ of our non-owner sample reported an interest in owning a sex doll.

\section{Between-Groups Analyses}

Exploring sexual attraction patterns, we ran a 2 (doll owner vs. comparison sample) $\times 3$ (adult-attracted vs. child-attracted vs. both-attracted) test of association to explore whether doll owners were any more or less likely than non-owners to be exclusively attracted to children. This test was statistically significant, $\chi^{2}(2)=9.54, p=.008$, Cramer's $V=0.22$. In examining the contingency table (Table 2), we saw that exclusive adult-directed attractions were slightly over-represented in the child-like doll owner sample compared to the figure that would be expected by chance. Contrastingly, exclusive attractions to children were slightly more prevalent than expected in the non-owner sample. Non-exclusive attractions were at the levels expected in each group. 
Table 2. Contingency table for that chi-square test related to (non-)exclusivity of attraction patterns among child-like doll owners and non-owner MAPs

\begin{tabular}{llccc}
\hline & & \multicolumn{2}{c}{ Group } & \\
\cline { 3 - 4 } Attraction Pattern & & Non-Owner & Doll Owner & Total \\
\hline Adult-only & Observed & 0 & 5 & 5 \\
& Expected & 2.94 & 2.06 & 5 \\
Children-only & Observed & 34 & 15 & 49 \\
& Expected & 28.82 & 20.18 & 49 \\
Both (non-exclusive) & Observed & 86 & 64 & 150 \\
& Expected & 88.24 & 61.76 & 150 \\
\hline
\end{tabular}

Note. 'Expected' counts reflect the values that would be expected if the observed number of people in each 'Attraction Pattern' category were proportionately distributed between the two samples.

We then ran a series of between-groups $t$-tests to explore differences between the groups on our measured variables. Descriptive statistics and details of the inferential findings are presented in Table 3. In these tests we see few differences between child-like doll owners and non-owner MAPs. However, doll owners were significantly less likely (to a moderate-tolarge degree) to express a proclivity for sexual abuse in relation to the full-form of the Interest in Child Molestation Scale, or specifically in relation to the questions pertaining to hypothetical arousal and behavioral intentions to engage in child sexual abuse. Doll owners were also less likely to demonstrate anxious attachment styles in comparison to non-owners. Finally, doll owners exhibited more obsessive-compulsive personality traits than non-owners in the comparison group. 
Table 3. Between-groups differences on measured variables

\begin{tabular}{|c|c|c|c|c|c|c|}
\hline & Group & $n$ & $M$ & $S D$ & $M_{\text {diff }}[95 \% \mathrm{CI}]$ & Inferential Test \\
\hline \multirow{2}{*}{ Partnered Sex Frequency (per month) } & Non-Owner & 114 & 1.29 & 3.78 & \multirow{2}{*}{$0.57[-0.67,1.81]$} & \multirow{2}{*}{$t(188)=0.90, p=.367, d=0.13$} \\
\hline & Doll Owner & 76 & 1.86 & 4.88 & & \\
\hline \multirow{2}{*}{ Interest in Child Molestation (Full) } & Non-Owner & 41 & 3.00 & 1.50 & \multirow{2}{*}{$-0.86[-1.49,-0.23]$} & \multirow{2}{*}{$t(77)=-2.71, p=.008, d=-0.61$} \\
\hline & Doll Owner & 38 & 2.14 & 1.31 & & \\
\hline \multirow{2}{*}{ Interest in Child Molestation (Arousal) } & Non-Owner & 41 & 3.94 & 1.76 & \multirow{2}{*}{$-1.32[-2.11,0.55]$} & \multirow{2}{*}{$t(77)=-3.39, p=.001, d=-0.76$} \\
\hline & Doll Owner & 38 & 2.61 & 1.72 & & \\
\hline \multirow{2}{*}{ Interest in Child Molestation (Behavior) } & Non-Owner & 41 & 2.05 & 1.31 & \multirow{2}{*}{$-0.64[-1.16,0.11]$} & \multirow{2}{*}{$t(77)=-2.41, p=.018, d=-0.54$} \\
\hline & Doll Owner & 38 & 1.42 & 1.01 & & \\
\hline \multirow{2}{*}{ Interest in Child Molestation (Enjoyment) } & Non-Owner & 41 & 3.16 & 1.80 & \multirow{2}{*}{$-0.79[-1.58,-0.00]$} & \multirow{2}{*}{$t(77)=-1.99, p=.051, d=-0.45$} \\
\hline & Doll Owner & 38 & 2.37 & 1.72 & & \\
\hline \multirow{2}{*}{ Sexual Self-Esteem } & Non-Owner & 112 & -0.11 & 0.88 & \multirow{2}{*}{$-0.01[-0.25,0.26]$} & \multirow{2}{*}{$t(184)=-0.04, p=.970, d=-0.01$} \\
\hline & Doll Owner & 74 & -0.12 & 0.96 & & \\
\hline \multirow{2}{*}{ Sexual Preoccupation } & Non-Owner & 113 & 0.31 & 0.83 & \multirow{2}{*}{$-0.06[-0.32,0.19]$} & \multirow{2}{*}{$t(187)=-0.48, p=.633, d=-0.07$} \\
\hline & Doll Owner & 76 & 0.25 & 0.92 & & \\
\hline \multirow{2}{*}{ Sexual Depression } & Non-Owner & 115 & -0.08 & 0.84 & \multirow{2}{*}{$-0.21[-0.46,0.05]$} & \multirow{2}{*}{$t(193)=-1.56, p=.120, d=-0.23$} \\
\hline & Doll Owner & 80 & -0.29 & 0.98 & & \\
\hline \multirow{2}{*}{ Emotionality } & Non-Owner & 118 & 0.45 & 1.20 & \multirow{2}{*}{$0.22[-0.12,0.56]$} & \multirow{2}{*}{$t(197)=1.29, p=.199, d=0.19$} \\
\hline & Doll Owner & 81 & 0.67 & 1.17 & & \\
\hline \multirow{2}{*}{ Schizotypal Personality } & Non-Owner & 108 & 2.23 & 0.50 & \multirow{2}{*}{$0.02[-0.15,0.18]$} & \multirow{2}{*}{$t(184)=0.20, p=.839, d=0.03$} \\
\hline & Doll Owner & 78 & 2.25 & 0.63 & & \\
\hline \multirow{2}{*}{ Borderline Personality } & Non-Owner & 108 & 2.46 & 0.51 & \multirow{2}{*}{$-0.05[-0.21,0.11]$} & $t(184)=-060 \quad n=547 d=-000$ \\
\hline & Doll Owner & 78 & 2.41 & 0.59 & & $(184)=-0.00, p=.04 /, a=-0.09$ \\
\hline Narcissistic Personality & Non-Owner & 108 & 2.29 & 0.55 & 002 Г_ 014 14 018$]$ & $t(184)-0$ \\
\hline Narcissisuc Personanty & Doll Owner & 78 & 2.31 & 0.53 & $0.02[-0.14,0.18]$ & $l(184)=0$ \\
\hline Avoidant Personality & Non-Owner & 108 & 2.21 & 0.56 & $0.13[-0.04,0.30]$ & $t(184)=1.49, p=.139, d=0.22$ \\
\hline & Doll Owner & 78 & 2.34 & 0.60 & & \\
\hline
\end{tabular}




\begin{tabular}{|c|c|c|c|c|c|c|}
\hline \multirow{2}{*}{ Obsessive-Compulsive Personality } & Non-Owner & 108 & 2.34 & 0.54 & \multirow{2}{*}{$0.22[0.05,0.38]$} & \multirow{2}{*}{$t(184)=2.59, p=.010, d=0.39$} \\
\hline & Doll Owner & 78 & 2.56 & 0.59 & & \\
\hline \multirow{2}{*}{ Antisocial Personality } & Non-Owner & 108 & 2.14 & 0.58 & \multirow{2}{*}{$-0.03[-0.20,0.15]$} & \multirow{2}{*}{$t(184)=-0.29, p=.769, d=-0.04$} \\
\hline & Doll Owner & 78 & 2.11 & 0.63 & & \\
\hline \multirow{2}{*}{ Secure Attachment } & Non-Owner & 108 & 4.47 & 1.40 & \multirow{2}{*}{$-0.40[-0.82,0.01]$} & \multirow{2}{*}{$t(185)=-1.90, p=.059, d=-0.28$} \\
\hline & Doll Owner & 79 & 4.07 & 1.49 & & \\
\hline \multirow{2}{*}{ Anxious-Insecure Attachment } & Non-Owner & 108 & 4.82 & 1.32 & \multirow{2}{*}{$-0.67[-1.07,-0.26]$} & \multirow{2}{*}{$t(185)=-3.24, p=.001, d=-0.48$} \\
\hline & Doll Owner & 79 & 4.15 & 1.48 & & \\
\hline \multirow{2}{*}{ Avoidant-Insecure Attachment } & Non-Owner & 108 & 3.56 & 1.26 & \multirow{2}{*}{$0.16[-0.21,0.52]$} & \multirow{2}{*}{$t(185)=0.83, p=.406, d=0.12$} \\
\hline & Doll Owner & 79 & 3.71 & 1.24 & & \\
\hline \multirow{2}{*}{ Sexual Objectification } & Non-Owner & 104 & 1.67 & 0.45 & \multirow{2}{*}{$0.09[-0.07,0.24]$} & \multirow{2}{*}{$t(178)=1.12, p=.263, d=0.17$} \\
\hline & Doll Owner & 76 & 1.75 & 0.57 & & \\
\hline
\end{tabular}

Note. Variables with scores that differ significantly between the groups are presented in bold typeface. 
We finished this first stage of analysis by looking at the relative levels of self-reported sexual offending among both samples, comparing the proportions of child-like doll owners and non-owner comparisons that reported engaging in non-consensual sexual activities with others, having sexual activity with a child, and obtaining or viewing indecent images of children. We ran a 2 (doll owner vs. comparison sample) × 3 ('yes', 'no', or 'unsure' in relation to past offending behaviors) test of association separately for each offense type. None of these tests were statistically significant, indicating similar proportions of self-reported offending in both samples (see Table 4):

- Non-consensual sex: $\chi^{2}(2)=1.95, p=.376$, Cramer's $V=0.11$

- Sexual activity with a child: $\chi^{2}(2)=0.66, p=.720$, Cramer's $V=0.06$

- Obtaining or viewing indecent images of children: $\chi^{2}(2)=3.34, p=.188$, Cramer's $V=0.14$ 
Table 4. Contingency table for the chi-square test related to relative proportions of selfreported sexual offending among child-like doll owners and non-owner MAPs

\begin{tabular}{|c|c|c|c|c|}
\hline \multirow[b]{2}{*}{ Offending } & & \multicolumn{2}{|c|}{ Group } & \multirow[b]{2}{*}{ Total } \\
\hline & & Non-Owner & Doll Owner & \\
\hline \multicolumn{5}{|c|}{ Non-consensual sex } \\
\hline \multirow[t]{2}{*}{ No } & Observed & 86 & 61 & 147 \\
\hline & Expected & 84.84 & 62.16 & 147 \\
\hline \multirow[t]{2}{*}{ Yes } & Observed & 8 & 10 & 18 \\
\hline & Expected & 10.39 & 7.61 & 18 \\
\hline \multirow[t]{2}{*}{ Unsure } & Observed & 7 & 3 & 10 \\
\hline & Expected & 5.77 & 4.23 & 10 \\
\hline \multicolumn{5}{|c|}{ Sexual activity with a child } \\
\hline \multirow[t]{2}{*}{ No } & Observed & 81 & 56 & 137 \\
\hline & Expected & 79.4 & 57.6 & 137 \\
\hline \multirow[t]{2}{*}{ Yes } & Observed & 16 & 15 & 31 \\
\hline & Expected & 17.97 & 13.03 & 31 \\
\hline \multirow[t]{2}{*}{ Unsure } & Observed & 5 & 3 & 8 \\
\hline & Expected & 4.64 & 3.36 & 8 \\
\hline \multicolumn{5}{|c|}{ Obtaining or using indecent images of children } \\
\hline \multirow[t]{2}{*}{ No } & Observed & 28 & 27 & 55 \\
\hline & Expected & 31.74 & 23.26 & 55 \\
\hline \multirow[t]{2}{*}{ Yes } & Observed & 63 & 36 & 99 \\
\hline & Expected & 57.14 & 41.86 & 99 \\
\hline \multirow[t]{2}{*}{ Unsure } & Observed & 10 & 11 & 21 \\
\hline & Expected & 12.12 & 8.88 & 21 \\
\hline
\end{tabular}

Note. 'Expected' counts reflect the values that would be expected if the observed number of people in each 'Offending' category were proportionately distributed between the two samples.

\section{Predicting 'Doll Owner' Group Membership}

To explore how our measured variables could distinguish between child-like doll owners and non-owning MAPs, we ran a binary logistic regression using age, exclusivity of attractions to children, and all our measured variables as predictors. The model was statistically significant and correctly classified $90.6 \%$ of participants into their correct group, Nagelkerke's pseudo- $R^{2}=0.79, \chi^{2}(20)=57.80, p<.001$.

Exploring the predictors of group membership (Table 5), we see that doll owners were significantly older than non-owners. They were also more likely to exhibit schizotypal 
personality traits, to report engaging in sexually objectifying behaviors than non-owners, and reported more anticipated enjoyment in relation to hypothetical child sexual abuse scenarios. However, they were significantly less sexually preoccupied than non-owners, less antisocial, and demonstrated a lower level of self-reported arousal to child sexual abuse scenarios. Doll owners were also less anxiously attached than non-owners.

Table 5. Binary logistic regression distinguishing doll owners from non-owner MAPs

\begin{tabular}{lccccc} 
Predictor & $\boldsymbol{B}$ & $\boldsymbol{S E}$ & $\boldsymbol{Z}$ & $\boldsymbol{p}$ & $\boldsymbol{O R}$ \\
\hline Intercept & -13.04 & 8.91 & -1.46 & .143 & $2.17 \mathrm{E}-06$ \\
Age & $\mathbf{0 . 1 2}$ & $\mathbf{0 . 0 6}$ & $\mathbf{1 . 9 9}$ & $\mathbf{. 0 4 7}$ & $\mathbf{1 . 1 2}$ \\
Exclusivity of Minor Attraction & -3.11 & 1.79 & -1.74 & .083 & 0.04 \\
Partner Sex Frequency (per month) & 0.04 & 0.12 & 0.29 & .770 & 1.04 \\
Interest in Child Molestation (Arousal) & $\mathbf{- 4 . 6 3}$ & $\mathbf{1 . 9 8}$ & $\mathbf{- 2 . 3 3}$ & $\mathbf{. 0 2 0}$ & $\mathbf{0 . 0 1}$ \\
Interest in Child Molestation (Behavior) & -2.65 & 1.46 & -1.82 & .070 & 0.07 \\
Interest in Child Molestation (Enjoyment) & $\mathbf{4 . 1 5}$ & $\mathbf{1 . 8 9}$ & $\mathbf{2 . 1 9}$ & $\mathbf{. 0 2 8}$ & $\mathbf{6 3 . 4 6}$ \\
Sexual Self-Esteem & 0.21 & 1.01 & 0.21 & .835 & 1.23 \\
Sexual Preoccupation & $\mathbf{- 3 . 9 3}$ & $\mathbf{1 . 8 7}$ & $\mathbf{- 2 . 1 1}$ & $\mathbf{. 0 3 5}$ & $\mathbf{0 . 0 2}$ \\
Sexual Depression & -0.12 & 1.19 & -0.10 & .921 & 0.89 \\
Emotionality & 2.53 & 1.52 & 1.67 & .095 & 12.55 \\
Schizotypal Personality & $\mathbf{5 . 1 4}$ & $\mathbf{2 . 3 7}$ & $\mathbf{2 . 1 7}$ & $\mathbf{. 0 3 0}$ & $\mathbf{1 7 1 . 5 1}$ \\
Borderline Personality & 0.87 & 1.27 & 0.68 & .494 & 2.38 \\
Narcissistic Personality & -2.11 & 1.55 & -1.37 & .171 & 0.12 \\
Avoidant Personality & 9.08 & 4.83 & 1.88 & .060 & 8790.17 \\
Obsessive-Compulsive Personality & -0.93 & 1.97 & -0.47 & .637 & 0.39 \\
Antisocial Personality & $\mathbf{- 8 . 0 7}$ & $\mathbf{3 . 8 4}$ & $\mathbf{- 2 . 1 0}$ & $\mathbf{. 0 3 6}$ & $\mathbf{3 . 1 4 E - 0 4}$ \\
Secure Attachment & -0.25 & 0.84 & -0.29 & .768 & 0.78 \\
Anxious-Insecure Attachment & $\mathbf{- 2 . 4 3}$ & $\mathbf{1 . 1 8}$ & $\mathbf{- 2 . 0 6}$ & $\mathbf{. 0 3 9}$ & $\mathbf{0 . 0 9}$ \\
Avoidant-Insecure Attachment & 0.14 & 0.71 & 0.20 & .843 & 1.15 \\
Sexual Objectification & $\mathbf{8 . 8 6}$ & $\mathbf{4 . 2 9}$ & $\mathbf{2 . 0 7}$ & $\mathbf{. 0 3 9}$ & $\mathbf{7 0 3 4 . 4 6}$ \\
\hline Note. B estimates represent the & & & &
\end{tabular}

Note. $B$ estimates represent the log odds of belonging to the 'doll owner' group. 'Exclusivity' variable coded as $0=$ non-exclusively attracted to children, $1=$ exclusively attracted to children. Significant predictors of group membership are presented in bold typeface. We have provided scientific notation for odds-ratios less than 0.00 to facilitate future meta-analyses. 


\section{Discussion}

In this work we have been able to present what we believe to be the first empirical analysis of child-like sex doll ownership. In doing so, we can begin to build a picture of who child-like doll owners are, their motivations for doll ownership, and the potential associations between such doll ownership and proclivities for the sexual abuse of children. This is of pivotal timing against a backdrop of philosophical and legal theorizing about the dangers of child-like doll ownership within an evidential vacuum (Brown \& Shelling, 2019; Chatterjee, 2020; Cox-George \& Bewley, 2018; Danaher, 2017, 2019; Strikwerda, 2017).

\section{Summary of Key Results}

In relation to owners' stated functions of child-like dolls, we found no evidence that sexual reasons were more highly endorsed than more emotional functions of dolls (e.g., dolls being used as a form of emotional intimacy or companionship). Other reasons for doll ownership included photography, non-sexual intimacy (e.g., for companionship), and nonsexual fantasy play, suggesting that the ownership of child-like dolls is far from a simplistic issue that can be explained by appealing to arguments related to sexual deviance. Among minor-attracted non-owners we observed interest in owning a child-like doll from $79.2 \%$ of participants, which is much higher than the observed rate of doll interest in teleiophilic populations (see Harper et al., 2022; Knox et al., 2017; Szczuka \& Krämer, 2016). This is perhaps unsurprising, though, given the nature of sexual attractions to children and the natural striving for some degree of sexual satisfaction. Within this context, it is also unsurprising that doll owners engaged in sexual activity with their dolls significantly more often than they engaged in partnered sexual activity. This is concordant with analyses of adult-like sex doll owners, who report engaging in sexual activity with their doll more often than having sex with a living partner (Harper et al., 2022), and with the broader sexological 
literature that suggests solitary masturbation is more frequent than partnered sexual activity (Herbenick et al., 2021).

In contemporary discourse around doll ownership, there is a tendency to frame doll sex ownership through a risk-based lens (Brown \& Shelling, 2019; Cox-George \& Bewley, 2018; Danaher, 2017, 2019). Within these discussions there is an implicit (and sometime explicit) assumption that the ownership of sex dolls - particularly dolls that resemble children - is inherently risky and associated with a proclivity for sexual offending. We found no such evidence of this within our data, with the behavioral proclivity and arousal to hypothetically engaging in child sexual abuse being lower among child-like sex doll owners than among MAPs who did not own a sex doll. This was even the case after controlling for their comparatively higher relative self-reported anticipated enjoyment of sexual engagement with children, and their higher rates of engaging in objectifying behaviors. As such, some of the concerns about child-like doll owners being at a greater risk of engaging in the sexual abuse of children might be misplaced. Indeed, when asking participants directly about their engagement with criminal activities, we found that there were no differences in self-reported offending between those who owned child-like dolls and those who did not.

From a personality perspective we found that child-like doll owners exhibited more schizotypal traits, but were less antisocial, than MAPs who did not own such dolls. Thinking about the traits of these two forms of personality this is perhaps unsurprising when considering the intimate relationships that sex doll owners commonly report having with their dolls (Langcaster-James \& Bentley, 2018; Valverde, 2012) That is, schizotypal personality traits are associated with social withdrawal and creative thinking (Moorman \& Samuel, 2018; Yasuyama et al., 2017), whereas antisocial traits are associated with disinhibition and interpersonal detachedness (Benning et al., 2003; Venables et al., 2014). Within this context it is understandable why higher levels of schizotypal traits and lower levels of antisocial trait 
might be more common personality profiles in doll owners, who appear to have more difficulties in forming relationships with real partners and fill this void with an emotional bond with their dolls (Lievesley et al., 2022). Although this could be questioned in the current sample owing to the minor-attracted nature of most participants, it should be noted that the doll owners in this work were no more likely to be exclusively attracted to children than those who did not own a doll, and so it is likely that any potential surrogacy of real relationships with bonds with dolls is better explained by their personality characteristics than by their sexual attraction patterns. We also found that doll owners were less likely to exhibit anxious attachment styles, suggesting a lesser need to form bonds with individual partners, and a reduced emphasis on the achievement of reassurance from others. Among doll owners this likely stems from an acknowledgement that they have a marginalized intimate lives and face disapproval and stigma from other. As such, interpersonal detachment might serve to protect doll owners from upset in everyday life, even if this means detachment from possible future intimate relationships.

\section{A Functional Model of Child-Like Doll Ownership?}

The findings presented here can begin to help us to link child-like doll ownership effects to the three models outlined in Harper et al. (2022). Central to at least two of these models is the association between doll ownership and risks of committing acts of sexual abuse, while the third model adopts a more interactive approach to motivations for, and effects of, doll ownership.

The 'dolls as protective' model would hypothesize that doll ownership would be associated with a lower level of sexual risk when compared to an appropriate non-owner comparison group. Although self-reported arousal levels (both in relation to responses to hypothetical child sexual abuse scenarios, and general levels of sexual preoccupation) were lower among doll owners than non-owning MAPs, we found no differences between the 
groups in self-reported behavioral intentions to engage in child molestation, or in selfreported past offending behaviors. As such, we did not find specific evidence for the 'dolls as protective' model.

According to the 'dolls as risky' model, we would expect those who own child-like sex dolls to demonstrate an increased proclivity for sexual offending. Although we found that doll owners engaged in more objectifying behaviors (e.g., staring at someone's body or evaluating their physical appearance) and reported a greater level of hypothetical enjoyment in abusing a child (as compared to MAPs who did not own dolls), we found no evidence of an increased proclivity to engage in sexual abuse. This was the case when considering both hypothetical behavioral intentions (as measured via the Interest in Child Molestation Scale; Gannon \& O'Connor, 2011) and self-reported past offending behaviors. As such, we did not find evidence for this risk-enhancing model of doll ownership.

The final model of doll ownership sees the motivations and effects of child-like sex dolls as functional and suggests that those who own such dolls do so because of some functional need that they have. As such, if dolls are to be seen as functional then their ownership will likely be unrelated to abuse proclivities at the group level (as reported above), but may be correlated with specific psychosocial or personality constructs. We did find evidence for this, with doll owners being less likely to have anxious attachment styles, which is indicative of a reduced need to be attached to intimate partners, and in some cases a desire to be relatively independent. At the group difference level, we also found that child-like doll owners exhibited more obsessive-compulsive personality traits than non-owners. This might indicate a need for order that is achievable by forming relationships with dolls (who are predictable and controllable) but not with living partners (who can be less predictable and controllable). Although this finding might be considered provisional in light of the poor psychometric outcomes associated with the Personality Styles Inventory (Hain et al., 2016), 
we believe that the ownership of child-like sex dolls may be explained by the functional roles (e.g., attachment formation, control over one's environment, safe sexual outlets related to preferred sexual targets) that such dolls can serve for some MAPs.

\section{Limitations and Future Directions}

One of the clearest limitations of the current study is its reliance on the self-report method of data collection. Although most psychological research uses this approach, topics such as child-like sex doll ownership are particularly susceptible to self-presentation biases in the context of ongoing legislative discussions about their criminalization (see Prostasia Foundation, 2021). We attempted to overcome a motivation for socially desirable responding by not tracking IP addresses of our participants, and by using SoSciSurvey, which is a survey platform that allows users to access online questionnaires using Tor browsers. However, it is still possible that some participants may have responded in such a way to avoid increased perceptions of the risks posed by those who own child-like sex dolls.

The data reported in this paper are cross-sectional and correlational, which inherently means that we cannot make causal arguments about the directions of the relationships reported earlier. Our observation that rates of arousal to child abuse scenarios were lower among doll owners, and that anticipated enjoyment of such hypothetical abuse was higher, might be inferred as doll ownership explaining such differences. Finding that child-like doll owners engage in more objectifying behaviors might be perceived as being the result of their owning of dolls. The finding that those who own dolls are less likely than non-owners to be sexually preoccupied might be suggested as the result of dolls satiating the sexual urges of their owners. However, the directional nature of these relationships is only able to be fully demonstrated using longitudinal designs that adopt a prospective approach. This is, researchers should collect baseline data in relation to these types of variables and to re-collect such data at regular timepoints following a doll's initial purchase. In doing this it would be 
possible to identify whether those who own dolls differ from non-owners in important ways even before they own a doll, or whether such differences emerge following (and, as such, because of) doll ownership.

Relatedly to this we did not ask participants about the type of dolls that they owned, which means that we cannot account for any differences that may be present between those who own simplistic inflatable dolls, inanimate silicone models, or dolls with embedded artificial intelligence. It is certainly plausible that each of these categories of doll are associated with different psychological profiles in relation to their owners, especially as people move away from purely sexual motivations and consider their dolls to be more akin to an intimate partner. Future work should look to explore this possibility.

In light of a possible functional use of child-like sex dolls, it might also be a useful direction for future research to explore the controlled use of such dolls among MAPs in therapeutic contexts. In this work we have not found any evidence that those who own childlike dolls are at an increased risk for sexual offending against children. We are also aware that MAPs struggle to achieve sexual satisfaction due to their attraction patterns and both the morality and legality of sexual contact with children (Mundy \& Cioe, 2019). Among nonowners in our sample, around $80 \%$ reported an interest in owning a doll. This suggests a potentially large pool of individuals who could gain from the functional benefits of dolls (e.g., the achievement of sexual satisfaction and the wellbeing benefits associated with this; Carcedo et al., 2020; Ward \& Gannon, 2006) without an increase in child abuse risk. Of course, there is also a possibility that having such a sexual outlet could reduce sexual preoccupation among MAPs who are currently unable to achieve sexual satisfaction, and that such a reduction could reduce motivations for sexual offending (for a theoretical model, see Seto, 2019). The hypothetical use of child-like dolls in sexual abuse prevention contexts has been raised previously (see Harper \& Lievesley, 2020; Rutkin, 2016), and future research 
might explore this possibility in well-controlled studies that embed ongoing measures of both risk and wellbeing to track the range of functional outcomes associated with doll ownership.

\section{Conclusions}

In this study we have presented what we believe to be the first empirical study into the psychological and risk-related constructs associated with the ownership of child-like sex dolls. In contrast to moralistic publications citing the potential risks of such dolls in related to child sexual abuse (Chatterjee, 2020; Danaher, 2017, 2019; Strikwerda, 2017), we found evidence for their functional use. In light of this, we hope that those working in psychological and sex science can launch systematic studies that explore how to best support MAPs in their search for safe sexual outlets, with ultimate aims of improving levels of mental health in this population and, subsequent to this, the prevention of the sexual abuse of children. 


\section{Declarations}

\section{Funding}

The authors received no funding for this research.

\section{Conflicts of interest}

The authors declare no conflicts of interest in relation to this work.

\section{Data availability}

To preserve the anonymity and confidentiality of those taking part in this exploratory work, the data related to this research is not publicly available.

\section{Code availability}

Not applicable. 


\section{References}

Arrigo, B. A., \& Purcell, C. E. (2001). Explaining paraphilias and lust murder: Toward an integrated model. International Journal of Offender Therapy and Comparative Criminology, 45(1), 6-31. https://doi.org/10.1177/0306624X01451002

Asbury, N. (2021, November 24). ODU professor steps down after firestorm over research into 'minor-attracted people'. The Washington Post. https://www.washingtonpost.com/education/2021/11/24/allyn-walker-odu-professorresigns/

Bartels, R. M., \& Merdian, H. M. (2016). The implicit theories of child sexual exploitation material users: An initial conceptualization. Aggression and Violent Behavior, 26, 1625. https://doi.org/10.1016/j.avb.2015.11.002

Benning, S. D., Patrick, C. J., Hicks, B. M., Blonigen, D. M., \& Krueger, R. F. (2003). Factor Structure of the Psychopathic Personality Inventory: Validity and Implications for Clinical Assessment. Psychological Assessment, 15(3), 340-350. https://doi.org/10.1037/1040-3590.15.3.340

Brown, R., \& Shelling, J. (2019). Exploring the implications of child sex dolls. Australian Institute of Criminology.

Carcedo, R. J., Fernández-Rouco, N., Fernández-Fuertes, A. A., \& Martínez-Álvarez, J. L. (2020). Association between sexual satisfaction and depression and anxiety in adolescents and young adults. International Journal of Environmental Research and Public Health, 17(3), e841. https://doi.org/10.3390/ijerph17030841

Chatterjee, B. B. (2020). Child sex dolls and robots: Challenging the boundaries of the child protection framework. International Review of Law, Computers \& Technology, 34(1), 22-43. https://doi.org/10.1080/13600869.2019.1600870 
Cox-George, C., \& Bewley, S. (2018). I, sex robot: The health implications of the sex robot industry. BMJ Sexual \& Reproductive Health, 44(3), 161-164. https://doi.org/10.1136/bmjsrh-2017-200012

Danaher, J. (2017). Robotic rape and robotic child sexual abuse: Should they be criminalised? Criminal Law and Philosophy, 11(1), 71-95. https://doi.org/10.1007/s11572-014-9362$\mathrm{X}$

Danaher, J. (2019). Regulating child sex robots: Restriction or experimentation? Medical Law Review, 27(4), 553-575. https://doi.org/10.1093/medlaw/fwz002

Dawson, D. L., Barnes-Holmes, D., Gresswell, D. M., Hart, A. J., \& Gore, N. J. (2009). Assessing the implicit beliefs of sexual offenders using the implicit relational assessment procedure: A first study. Sexual Abuse, 21(1), 57-75. https://doi.org/10.1177/1079063208326928

Diamond, M., Jozifkova, E., \& Weiss, P. (2011). Pornography and sex crimes in the Czech Republic. Archives of Sexual Behavior, 40, 1037-1043. https://doi.org/10.1007/s10508010-9696-y

Ferguson, A. (2014). The sex doll: A history. McFarland \& Company, Inc.

Ferguson, C. J., \& Hartley, R. D. (2009). The pleasure is momentary ... the expense damnable? The influence of pornography on rape and sexual assault. Aggression and Violent Behavior, 14(5), 323-329. https://doi.org/10.1016/j.avb.2009.04.008

Ferguson, C. J., \& Hartley, R. D. (2022). Pornography and sexual aggression: Can metaanalysis find a link? Trauma,. Violence, \& Abuse, 23(1), 278-287. https://doi.org/10.1177/1524838020942754

Fergusson, D., McLeod, G., Horwood, L., Swain, N., Chapple, S., \& Poulton, R. (2015). Life satisfaction and mental health problems (18 to 35 years). Psychological Medicine, 45(11), 2427-2436. https://doi.org/10.1017/S0033291715000422 
Gannon, T. A., \& O'Connor, A. (2011). The development of the interest in child molestation scale. Sexual Abuse, 23(4), 474-493. https://doi.org/10.1177/1079063211412390

Geary, D. C., \& Flinn, M. V. (2001). Evolution of human parental behavior and the human family. Parenting, 1(1-2), 5-61. https://doi.org/10.1080/15295192.2001.9681209

Gervais, S. J., Davidson, M. M., Styck, K., Canivez, G., \& DiLillo, D. (2018). The development and psychometric properties of the Interpersonal Sexual Objectification Scale-Perpetration Version. Psychology of Violence, 8(5), 546-559. https://doi.org/10.1037/vio0000148

Gillath, O., Hart, J., Noftle, E. E., \& Stockdale, G. D. (2009). Development and validation of a state adult attachment measure (SAAM). Journal of Research in Personality, 43(3), 362-373. https://doi.org/10.1016/j.jrp.2008.12.009

Hain, S., Schermelleh-Engel, K., Freitag, C., Louwen, F., \& Oddo, S. (2016). Development of a short form of the Personality Styles and Disorder Inventory (PSDI-6): Initial validation in a sample of pregnant women. European Journal of Psychological Assessment, 32(4), 283-290. https://doi.org/10.1027/1015-5759/a000260

Hall, P. (2021). The moral maze of sex and porn addiction. Addictive Behaviors, 123, e107054. https://doi.org/10.1016/j.addbeh.2021.107054

Harper, C. A., \& Lievesley, R. (2020). Sex doll ownership: An agenda for research. Current Psychiatry Reports, 22(10), e54. https://doi.org/10.1007/s11920-020-01177-w

Harper, C. A., Lievesley, R., \& Wanless, K. (2022). Exploring the psychological characteristics and risk-related cognitions of individuals who own sex dolls. The Journal of Sex Research. https://doi.org/10.1080/00224499.2022.2031848

Herbenick, D., Rosenberg, M., Golzarri-Arroyo, L., Fortenberry, J. D., \& Fu, T.-c. (2021). Changes in penile-vaginal intercourse frequency and sexual repertoire from 2009 to 
2018: Findings from the national survey of sexual health and behavior. Archives of Sexual Behavior. https://doi.org/10.1007/s10508-021-02125-2

Knox, D., Huff, S., \& Chang, I. J. (2017). Sex dolls - creepy or healthy? Attitudes of undergraduates. Journal of Positive Sexuality, 3(2), 32-37. https://doi.org/10.1108/JOSM-05-2020-0145

Langcaster-James, M., \& Bentley, G. (2018). Beyond the sex doll: Post-human companionship and the rise of the 'allodoll.' Robotics, 7(4), e62. https://doi.org/10.3390/robotics7040062

Lievesley, R., Reynolds, R., \& Harper, C. A. (2022). The 'perfect' partner: Understanding the lived experiences of sex doll owners. PsyArXiv Preprint. https://doi.org/10.31234/osf.io/nmuqs

Middleweek, B. (2021). Male homosocial bonds and perceptions of human-robot relationships in an online sex doll forum. Sexualities, 24(3), 370-387. https://doi.org/10.1177/1363460720932383

Mihalides, S., Devilly, G. J., \& Ward, T. (2004). Implicit cognitive distortions and sexual offending. Sexual Abuse, 16(4), 333-350. https://doi.org/10.1177/107906320401600406 Moen, O. M., Sterri, A. B. (2018). Pedophilia and computer-generated child pornography. In D. Boonin (Ed.), The Palgrave handbook of philosophy and public policy (pp. 369381). Palgrave Macmillan. https://doi.org/10.1007/978-3-319-93907-0_29

Moorman, E. L., \& Samuel, D. B. (2018). Representing schizotypal thinking with dimensional traits: A case for the Five Factor Schizotypal Inventory. Psychological Assessment, 30(1), 19-30. https://doi.org/10.1037/pas0000497

Mundy, C. L., \& Cioe, J. D. (2019). Exploring the relationship between paraphilic interests, sex, and sexual and life satisfaction in non-clinical samples. The Canadian Journal of Human Sexuality, 28(3), 304-316. https://doi.org/10.3138/cjhs.2018-0041 
Pfaus, J. G., Quintana, G. R., Mac Cionnaith, C. E., Gerson, C. A., Dubé, S., \& Coria-Avila, G. A. (2020). Conditioning of sexual interests and paraphilias in humans is difficult to see, virtually impossible to test, and probably exactly how it happens: A comment on Hsu and Bailey (2020). Archives of Sexual Behavior, 49, 1403-1407. https://doi.org/10.1007/s10508-020-01739-2

Prostasia Foundation. (2021). Our campaigns against doll bans. Retrieved from https://prostasia.org/sex-doll-laws/

Rubin, M. (2017). Do $p$ values lose their meaning in exploratory analyses? It depends how you define the familywise error rate. Review of General Psychology, 21, 269-275. https://doi.org/10.1037/gpr0000123

Rutkin, A. (2016). Could sex robots and virtual reality treat paedophilia? New Scientist. https://www.newscientist.com/article/2099607-could-sex-robots-and-virtual-realitytreat-paedophilia/

Seto, M. C. (2019). The motivation-facilitation model of sexual offending. Sexual Abuse, 31(1), 3-24. https://doi.org/10.1177/1079063217720919

Seto, M. C., \& Eke, A. W. (2005). The criminal histories and later offending of child pornography offenders. Sexual Abuse, 17, 201-210. https://doi.org/10.1007/s11194$005-4605-y$

Seto, M. C., Hanson, R. K., \& Babchishin, K. M. (2011). Contact sexual offending by men with online sexual offenses. Sexual Abuse, 23(1), 124-145. https://doi.org/10.1177/1079063210369013

Snell, W. E., \& Papini, D. R. (1989). The sexuality scale: An instrument to measure sexualesteem, sexual-depression, and sexual-preoccupation. The Journal of Sex Research, 26(2), 256-263. https://doi.org/10.1080/00224498909551510 
Strikwerda, L. (2017). Legal and moral implications of child sex robots. In J. Danaher \& N. McArthur (Eds.), Robot Sex: Social and ethical implications (pp. 133-152). MIT Press.

Su, N. M., Lazar, A., Bardzell, J., \& Bardzell, S. (2019). Of dolls and men: Anticipating sexual intimacy with robots. ACM Transactions on Computer-Human Interaction, 26(3), e13. https://doi.org/10.1145/3301422

Szczuka, J. M., \& Krämer, N. C. (2016, December 19). Influences on the intention to buy a sex robot. Paper presented at the International Conference on Love and Sex with Robots. London, UK.

Valverde, S. (2012). The modern sex doll owner: A descriptive analysis [Master's, California Polytechnic State University]. https://digitalcommons.calpoly.edu/theses/849

Venables, N., Hall, J., \& Patrick, C. (2014). Differentiating psychopathy from antisocial personality disorder: A triarchic model perspective. Psychological Medicine, 44(5), 1005-1013. https://doi.org/10.1017/S003329171300161X

Ward, T., \& Gannon, T. A. (2006). Rehabilitation, etiology, and self-regulation: The comprehensive good lives model of treatment for sexual offenders. Aggression and Violent Behavior, 11(1), 77-94. https://doi.org/10.1016/j.avb.2005.06.001

Ward, T., \& Keenan, T. (1999). Child molesters' implicit theories. Journal of Interpersonal Violence, 14(8), 821-838. https://doi.org/10.1177/088626099014008003

Ward, T., \& Marshall, W. L. (2004). Good lives, aetiology and the rehabilitation of sex offenders: A bridging theory. Journal of Sexual Aggression, 10(2), 153-169. https://doi.org/10.1080/13552600412331290102

Watson, D., Clark, L. A., \& Tellegen, A. (1988). Development and validation of brief measures of positive and negative affect: The PANAS scales. Journal of Personality and Social Psychology, 54(6), 1063-1070. https://doi.org/10.1037/0022-3514.54.6.1063 
Yasuyama, T., Ohi, K., Shimada, T., Uehara, T., \& Kawasaki, Y. (2017). Differences in social functioning among patients with major psychiatric disorders: Interpersonal communication is impaired in patients with schizophrenia and correlates with an increase in schizotypal traits. Psychiatry Research, 249, 30-34. https://doi.org/10.1016/j.psychres.2016.12.053 